\title{
Ultrasound-guided foam sclerotherapy for chronic venous disease with ulcer. A prospective multiple outcome cohort study*
}

\author{
Escleroterapia ecoguiada com espuma para doença venosa crônica com úlcera: \\ coorte prospectiva de múltiplos desfechos
}

\begin{abstract}
Guilherme Camargo Gonçalves de Abreu (D), Otacílio de Camargo Jr.' (D), Márcia Fayad Marcondes de Abreu² (D),
\end{abstract} José Luis Braga de Aquino'

\begin{abstract}
Background: Chronic Venous Disease (CVD) is the main cause of chronic leg ulcers. Varicose veins are the most frequent cause of venous leg ulcers (VLU). 50.9\% of Brazilian women have varicose veins and ulcer prevalence is as high as 4\%. Ultrasound-guided foam sclerotherapy (UGFS) is a low-cost treatment option for varicose veins. Objectives: To analyze UGFS outcomes in patients with VLU. Methods: Prospective consecutive single center cohort study. Patients with great saphenous vein (GSV) reflux and VLU were treated and followed-up for 180 days. The following were studied: quality of life (QoL), disease severity, healing, and elimination of GSV reflux. The Aberdeen questionnaire, a venous clinical severity score, and Duplex scanning (DS) results were analyzed. Results: 22 patients aged 35 to 70 years were treated. There was improvement in quality of life, disease severity reduced, and ulcer diameter reduced $(p<0.001 ;$ ANOVA). $77.27 \%$ of VLU healed completely ( $95 \% \mathrm{Cl}$ : 59.76-94.78\%). The dimensions of 20/22 VLU reduced ( $90.91 \%$; 95\%Cl: 78.9-100\%). GSV reflux was eliminated in 63.64\% (95\%Cl: 43.54-83.74\%). Men had greater QoL benefit and women had more complications. There were no severe complications. The VLU that had healed completely at the end of the study were smaller at baseline than those that did not completely heal. The GSV that were completely occluded at the end of the study were smaller at baseline than those that were not completely occluded ( $p<0.05$; Mann-Whitney). Conclusion: The results suggest that most patients benefited from UGFS.
\end{abstract}

Keywords: varicose ulcer; leg ulcer; varicose veins; sclerotherapy; ultrasonography; quality of life.

\begin{abstract}
Resumo
Contexto: A doença venosa crônica (DVC) é a principal causa de úlceras crônicas em membros inferiores. As varizes dos membros inferiores são a causa mais frequente de úlcera venosa (UV). No Brasil, 50,9\% das mulheres têm varizes e a prevalência da úlcera chega a 4\%. A escleroterapia ecoguiada com espuma (EEE) é uma alternativa de baixo custo para tratamento de varizes de membros inferiores. Objetivos: Analisar evolução de portadores de UV tratados com EEE. Métodos: Coorte prospectiva e consecutiva em um único serviço. Portadores de UV com veia safena magna (VSM) insuficiente foram acompanhados por 180 dias após EEE. Foram estudadas: qualidade de vida, gravidade da doença, cicatrização e eliminação do refluxo. Foram utilizados questionário Aberdeen, escore clínico venoso e ultrassom Doppler. Resultados: Foram tratados 22 pacientes com idade entre 35 a 70 anos. Houve melhora na qualidade de vida, redução da gravidade da doença, e redução dos diâmetros das úlceras ( $p<0.001$; ANOVA). Houve redução das dimensões em 90,91\% das úlceras [intervalo de confiança de 95\% (IC95\%) 78,9-100\%], e cicatrização completa em $77,27 \%$ (IC95\% 59,76-94,78\%). O refluxo foi eliminado em 63,64\% (IC95\% 43,54-83,74\%) das VSM. Homens tiveram maior benefício em qualidade de vida, e mulheres apresentaram mais complicações. Não houve complicações graves. As UV completamente cicatrizadas e as VSM que apresentaram oclusão completa apresentavam dimensões inicialmente menores quando comparadas às das UV não completamente cicatrizadas e das VSM não completamente ocluídas ( $p<0,05$; Mann-Whitney). Conclusões: Os resultados sugerem que EEE foi benéfica para a maioria dos pacientes.
\end{abstract}

Palavras-chave: varizes; insuficiência venosa; úlcera varicosa; escleroterapia; ultrassonografia; qualidade de vida.

How to cite: Abreu GCG, Camargo Jr. O, Abreu MFM, Aquino JLB. Ultrasound-guided foam sclerotherapy for chronic venous disease with ulcer. A prospective multiple outcome cohort study. J Vasc Bras. 2020;19: e20180108. https://doi. org/10.1590/1677-5449.180108 \footnotetext{
Pan-american Congress of Vascular and Endovascular Surgery (2016)

1 Pontifícia Universidade Católica de Campinas - PUC-Campinas, Campinas, SP, Brasil.

${ }^{2}$ Hospital e Maternidade Celso Pierro, Serviço de Cirurgia Vascular e Endovascular, Campinas, SP, Brasil.

Financial support: None.

Conflicts of interest: No conflicts of interest declared concerning the publication of this article

Submitted: April 12, 2019. Accepted: September 15, 2019.
}

* The article was based on dissertation approved by the Programa de Pós-graduação em Ciências da Saúde, PUC-Campinas (2017), and was presented at the XIV 


\section{INTRODUCTION}

Chronic Venous Disease (CVD) is the main cause of lower limb chronic ulcers. ${ }^{1}$ Primary varicose veins with great saphenous vein (GSV) reflux is the most frequently identified condition in patients with venous ulcers (VU). ${ }^{2}$ It is estimated that $6 \%$ of patients with varicose veins will develop $\mathrm{VU}$ at some point in their lives. ${ }^{3}$ In Brazil, $50.9 \%$ of women and $37.9 \%$ of men have varicose veins and the prevalence of $\mathrm{VU}$ is as high as 3.6\%. ${ }^{4}$ From 2009 to 2013, the Brazilian government spent about 125 million US Dollars on treatment and social security benefits for patients because of varicose veins and its complications. ${ }^{5,6}$ Specialized services improve rates of VU healing and reduce ulcer prevalence. ${ }^{7,8}$ Varicose vein surgery is considered economically advantageous for reducing VU recurrence. ${ }^{9}$

Treatment of primary CVD through compression therapy does not solve venous reflux. Compression is associated with healing of $65 \%$ of ulcers within 24 weeks, but up to $70 \%$ of the patients have VU recurrence when they end treatment. ${ }^{10-14}$ Surgery improves quality of life in varicose veins patients. ${ }^{15}$ Resection of insufficient GSVs reduces recurrence of VU. ${ }^{12,16,17}$ Foam sclerotherapy can provoke occlusion of over $80 \%$ of GSVs treated. ${ }^{18,19}$ Brittenden et al. reported $54 \%$ occlusion of veins in a large randomized trial. ${ }^{20}$ Divergent results are probably a reflection of heterogeneous anatomical and clinical characteristics in the populations studied. Furthermore, there is not merely one uniform foam sclerotherapy method. Controlled trials identify lower reflux cessation rates and higher reintervention rates after sclerotherapy when compared with surgery and thermoablation. ${ }^{20,21}$ Controlled trials also demonstrate that frequencies of adverse effects are similar after surgery and thermoablation. ${ }^{21,22}$ Notwithstanding the inferior result in terms of reflux cessation, patients treated with sclerotherapy present less pain, better quality of life, and a faster return to daily activities than patients treated surgically. ${ }^{19,21,23}$ Cost analyses favor sclerotherapy over other methods. ${ }^{21,24}$

\section{OBJECTIVES}

To investigate quality of life, ulcer healing and venous disease severity after foam sclerotherapy treatment and investigate factors related to main outcomes.

\section{METHODS}

Prospective and consecutive single center cohort with systematic follow-up and data collection protocol. All patients with non-healing venous ulcers and primary reflux of the GSV treated at the Hospital run by the Pontifícia Universidade Católica de Campinas (PUC-Campinas), Campinas, SP, Brazil, from June 2015 to June 2016. The study was approved by the ethics committee at the Pontifícia Universidade Católica de Campinas (PUC-Campinas). Only patients who were able to understand the risks and benefits and agreed to take part were included. We defined pathological reflux as duration greater than half a second and extension exceeding $20 \mathrm{~cm}$ on a great saphenous vein Duplex scan (DS) performed standing up..$^{25}$ MedisonSonoace Pico and Siemens Acuson X300 PE equipment were used. A certificated researcher performed all examinations. We defined venous ulcer as an open wound of at least $1 \mathrm{~cm}$ diameter on the skin of the leg or foot, in areas with venous hypertension. Clinical examination was confirmed by $\mathrm{DS}^{26}$ (Figure 1).

The exclusion criteria were:

- Peripheral arterial obstructive disease;

- Venous thromboembolism

- Foramen ovale;

- Pregnancy;

- Allergy to polidocanol;

- Infection in the lower limbs;

- Deep vein obstruction (by Duplex scan);

- Age less than 18 years;

- Patients who were unable to walk or were confined to bed;

- Patients with unfavorable clinical conditions.

The following were evaluated: quality of life, venous disease severity, ulcer size, and venous status at baseline before treatment and at 60 days and 180 days after treatment. Versions of the Aberdeen questionnaire for venous disease (AQ) and the venous clinical severity score (VCSS) translated and validated for our language were used. ${ }^{27-29}$ Ulcer healing was evaluated by the largest ulcer diameter. Venous status was characterized by DS. Clinical, anthropometric, anatomical, and social data were collected (Figure 2).

In each session, $10 \mathrm{ml}$ of foam was injected straight into the GSV with a single puncture. Puncture and foam progression were monitored by DS. Foam was produced by mixing $8 \mathrm{ml}$ of room air with $2 \mathrm{ml}$ of $3 \%$ polidocanol solution (Victalab).

Elastic bandages were applied after injections. Patients were instructed to keep the compression bandages on for 24 hours and wear 20 to $30 \mathrm{mmHg}$ thigh-high compression stockings after removing the 


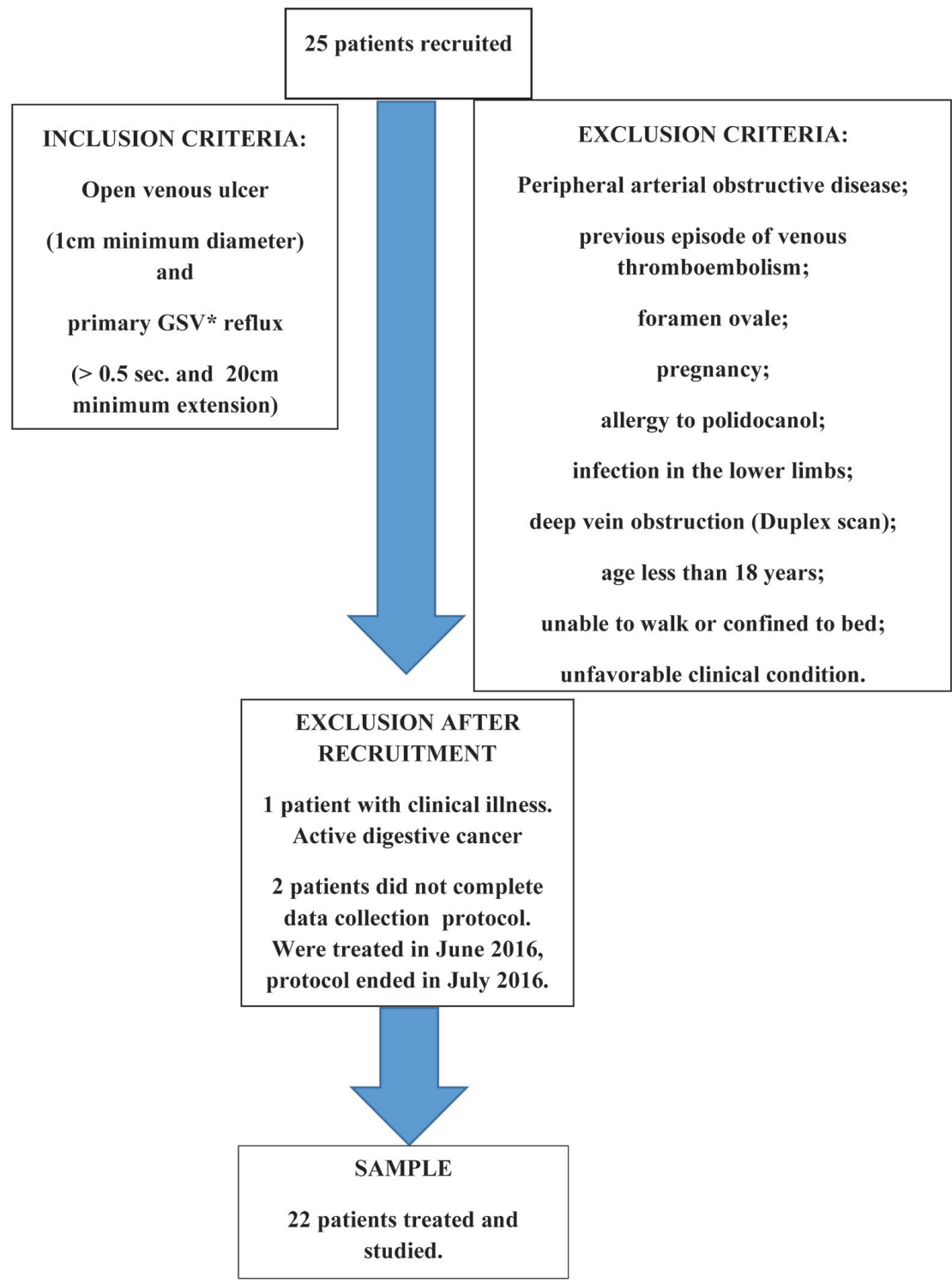

Figure 1. Sample flowchart. *Great saphenous vein.

bandages. Patients were told to maintain their daily habits. Up to four treatment sessions were performed if there was persistent great saphenous vein reflux and if ulcer dimensions remained unchanged.

\section{Data analysis}

Quality of life (assessed by AQ), severity score, and ulcer diameters evaluated at pre-treatment baseline and 60 days and 180 days after treatment were compared using repeated measures ANOVA on ranks (non-parametric method). Interactions between clinical variables and outcomes were also evaluated by ANOVA on ranks. Results for QoL, VCCS, and VU healing were classified as: improvement, no improvement, or worsening. Frequencies were described at each follow-up point, 60 and 180 days after treatment. Results of the great saphenous vein treatment were classified as complete or not complete occlusion and presence or absence of residual reflux. Results classified by categories were expressed as frequencies for each follow-up point. Patients were grouped according to outcome (VU healing, occlusion and cessation of reflux in the GSV, and occurrence of adverse effects). Continuous variables were compared using the Mann-Whitney test and categorical variables were compared using Fischer's test. A 5\% statistical significance level was adopted. The Statistical Analysis System for Windows 9.4 (SAS Institute Inc., Cary, NC, USA) and Minitab 16 were used for statistical analysis. 


\section{PATIENTS TREATED AND STUDIED}

3rd step - 30 days after step 2

DATA COLLECTION AND TREATMENT

Medical interview - adverse effects

Clinical assessment

1. Ulcer measurement and photo

2. Duplex scan

Foam sclerotherapy if the ulcer remains the same as step 2 and the saphenous vein remains patent with reflux

5th step; 90 days after step2

DATA COLLECTION AND TREATMENT

Medical interview - adverse effects

Clinical assessment

1. Ulcer measurement and photo

2. Duplex scan

Foam sclerotherapy if the ulcer remains the same as step

2 and the saphenous vein remains patent with reflux

2nd step - 7 days after step 1

DATA COLLECTION AND TREATMENT

1. Aberdeen venous questionnaire

2. Venous clinical severity score

3. Ulcer measurement and photo

4. Foam sclerotherapy

4th step; 60 days after step2

DATA COLLECTION AND TREATMENT

Medical interview - adverse effects

Clinical assessment:

1. Aberdeen venous questionnaire

2. Venous clinical severity score

3. Ulcer measurement and photo

4. Duplex scan

Foam sclerotherapy if the ulcer remains the same as step 2 and the saphenous vein remains patent with reflux

6th step; 180 days after step2

DATA COLLECTION

Medical interview - adverse effects

Clinical assessment

1. Aberdeen venous questionnaire

2. Venous clinical severity score

3. Ulcer measurement and photo

4. Duplex scan

\section{DATA ANALYSIS}

Figure 2. Protocol flowchart.

\section{RESULTS}

Twenty-two patients were treated consecutively. There were no losses. There were 42 treatments (1.9+/- 0.9 application per patient). Most patients were obese or overweight, BMI varied between 23 and 45 $(30+/-1)$, and only 3 patients $(14 \%)$ had normal weight (BMI between 18.5 and 24.9). Ten patients $(45 \%)$ did not have comorbidities whereas twelve (55\%) patients did (Tables 1 and 2). Thirteen patients $(59 \%)$ had no adverse effects. There were eleven adverse effects in nine patients, all of them female. Among the women, $60 \%$ had at least one adverse effect and 20\% exhibited staining along the path of the vein treated. All adverse effects were mild and treated on an outpatient basis. There was a higher proportion of women in the group that presented at least one adverse effect ( $\mathrm{P}=0.017$; Fisher). Other anatomical, clinical and social variables did not differ between these groups (with or without adverse effects) (Table 3). 
Table 1. Distribution of number of administrations per patient.

\begin{tabular}{ccc}
\hline Patient (\%) & Number of administrations & Total administrations \\
\hline $8(36.4 \%)$ & 1 & 8 \\
$10(45.5 \%)$ & 2 & 20 \\
$2(9.1 \%)$ & 3 & 6 \\
$2(9.1 \%)$ & 4 & 8 \\
$22(100 \%)$ & & 42 \\
\hline
\end{tabular}

Table 2. Measures of position (average and median) and dispersion (standard deviation, minimum and maximum) of numerical variables.

\begin{tabular}{|c|c|c|c|c|c|}
\hline Variable & Mean & Sd $\$ S$ & Min & Median & Max \\
\hline Administrations (n) & 1.91 & 0.92 & 1.00 & 2.00 & 4.00 \\
\hline Age (years) & 56.05 & 10.46 & 35.00 & 58.50 & 70.00 \\
\hline Schooling (years) & 6.36 & 4.39 & 0.00 & 6.00 & 15.00 \\
\hline Baseline AQ* & 47.05 & 12.17 & 21.70 & 45.00 & 74.20 \\
\hline Day $60 \mathrm{AQ}^{*}$ & 23.96 & 10.29 & 6.30 & 21.20 & 48.20 \\
\hline Day $180 \mathrm{AQ}^{*}$ & 16.99 & 9.58 & 0.00 & 16.40 & 37.00 \\
\hline Baseline VCSS† & 18.64 & 3.03 & 14.00 & 19.00 & 24.00 \\
\hline Day 60 VCSSt & 10.09 & 4.76 & 3.00 & 9.00 & 20.00 \\
\hline Day 180 VCSS & 6.73 & 3.61 & 1.00 & 6.00 & 16.00 \\
\hline VUキ baseline diameter $(\mathrm{cm})$ & 4.11 & 3.40 & 1.00 & 3.00 & 14.00 \\
\hline VUキ day 60 diameter $(\mathrm{cm})$ & 1.15 & 2.52 & 0 & 0 & 8.0 \\
\hline $\mathrm{VU} \neq$ day 180 diameter $(\mathrm{cm})$ & 1.18 & 2.65 & 0 & 0 & 10.0 \\
\hline GSV $\neq \neq$ baseline diameter $(\mathrm{mm})$ & 12.00 & 3.62 & 5.50 & 11.05 & 21.00 \\
\hline BMIS $\left(\mathrm{kg} / \mathrm{m}^{2}\right)$ & 30.2 & 5.4 & 23.1 & 30.3 & 44.7 \\
\hline
\end{tabular}

*Aberdeen venous questionnaire; $\uparrow$ Venous clinical severity score; $\neq$ Larger venous ulcer diameter; $\neq \neq$ Great saphenous vein, $\$$ Body mass index., $\$ \$$ standard deviation.

Table 3. Distribution of adverse effects (AE) per patient ( $n)$.

\begin{tabular}{lcc}
\hline \multicolumn{1}{c}{ Adverse Effect } & $\mathbf{n}$ & Patient with AE (n) \\
\hline Phlebitis with pain & 4 & $3^{*}, 13^{*}, 15^{*}, 19^{*}(4)$ \\
Phlebitis without pain & 2 & $2^{*}, 4^{*}(2)$ \\
Skin staining & 3 & $4^{*}, 12^{*}, 15^{*}(3)$ \\
Local pain & 1 & $22^{*}$ \\
Local cellulitis & 1 & $16^{*}(1)$ \\
Total AE & 11 & $2^{*}, 3^{*}, 4^{*}, 12^{*}, 13^{*}, 15^{*}, 16^{*}, 19^{*}, 22^{*}(9)$ \\
\hline
\end{tabular}

* Patient affected by adverse effect.

\section{Quality of life}

Twenty-one patients (95.45\%; 95\%CI: 86.75-100\%) exhibited QoL improvement (reduction in AQ) by day 60. On day 180, all $22(100 \%)$ patients had improved QoL compared to baseline. Five patients (22.73\%; 95\%CI: 5.22-42.24\%) had deterioration of QoL from day 60 to day 180. Overall, QoL improved over time ( $\mathrm{p}<0.001$; ANOVA). There was an interaction between the number of UGFS sessions and quality of life ( $\mathrm{p}$-value $=0.0253$ ). The worse the QoL assessed on day 60, the more treatment sessions the patients needed $(\rho=0.5449$, p-value $=0.0087$, Spearman). There was an interaction between gender and QoL progress $(\mathrm{p}=0.0309)$. There were no differences in men's and women's pre-treatment
QoL (p-value $=0.9438 ;$ Mann-Whitney) or day 60 QoL ( $\mathrm{p}=0.1805$; Mann-Whitney). On day 180, men's QoL was better than women's ( $p=0.0074$; Mann-Whitney). Both genders exhibited quality of life improvement over time ( $<<0.001$; ANOVA); however, women's QoL did not change from day 60 to day $180(p=0.0884)$. Among men, there were improvements at each evaluation $(\mathrm{p}<0001$ baseline to day 60 , p-value $<0.001$ baseline to day 180 , $\mathrm{p}=0.0393$ from day 60 to day 180). The variables body mass index (BMI), GSV reflux pattern, VU diameter, GSV diameter, reflux in other venous territories, age, comorbidities, side affected by VU, educational level, and occupation did not have any significant influence. 


\section{Clinical disease severity}

Twenty-one patients (95\%; 95\% CI: 86.75-100\%) exhibited reduction in severity by day 60 . All $22(100 \%)$ patients exhibited reduction in severity by day 180 . Three (14\%; 95\%CI: 0-27.98\%) exhibited deterioration between the evaluations on day 60 and day 180 . Overall, severity reduced over time $(\mathrm{p}<0.001$;

Table 4. Frequency, percentage of ulcer healing and Confidence interval.

\begin{tabular}{lcc}
\hline \multicolumn{1}{c}{ Ulcer healing } & $\mathbf{n}$ & $\%(\mathbf{9 5} \% \mathbf{C l}+)$ \\
\hline Day 60 & & \\
Complete & 15 & $68.18(48.72-87.64 \%)$ \\
Incomplete & 07 & $31.82(12.36-52.28 \%)$ \\
Failure & 0 & 0 \\
Day 180 & & \\
Complete & 17 & $77.27(59.75-94.79 \%)$ \\
Incomplete & 03 & $13.64(0-27.98 \%)$ \\
Failure & 02 & $9.09(0-21.10 \%)$ \\
\hline
\end{tabular}

† Confidence interval

Table 5. Influence of variables on reduction in ulcer diameter.

\begin{tabular}{lcc}
\hline \multicolumn{1}{c}{ Variable } & Interaction & p-value \\
\hline BMI* $^{*} 0.5877$ & 0.2897 \\
GSV† reflux pattern & 0.4524 & 0.3242 \\
GSV† diameter & 0.9529 & 0.8751 \\
Reflux in perforating veins & 0.1991 & 0.2858 \\
Reflux in deep veins & 0.3636 & 0.2322 \\
Number of applications & 0.6992 & 0.9772 \\
Gender & 0.1002 & 0.0801 \\
Age (years) & 0.2449 & 0.1497 \\
Comorbidity & 0.2292 & 0.2243 \\
Side affected by ulcer & 0.9873 & 0.6225 \\
Schooling (years) & 0.5385 & 0.5509 \\
Occupation & 0.3349 & 0.1305 \\
\hline
\end{tabular}

ANOVA on ranks *Body mass index; $†$ Great saphenous vein.
ANOVA). Patients who had larger ulcers $(\rho=0.4350$, $p$-value $=0.0430)$, older patients $(\rho=0.4323$; $p$-value $=0.0445)$, women $(p-v a l u e=0.0357)$, and those on sick leave $(\mathrm{p}$-value $=0.0143)$ had more severe disease. The variables BMI, GSV reflux pattern, GSV diameter, reflux in other venous territories, number of treatment sessions administered to patients, comorbidities, side affected by VU, and educational level did not have any significant influence on the course of clinical severity.

\section{Venous ulcer}

At baseline, all patients had non healing VU. On day 60, 15/22 VU (68.18\%; 95\%CI: 48.72-87.64\%) had healed completely and the remainder were all smaller. On day 180, 17/22 (77.27\%; 95\%CI: 59.76-94.78\%) ulcers had healed completely. Between day 60 and day 180 assessments, $3 / 22$ (13.64\% 95\% CI: 0-27.98\%) VU increased in size. There was no recurrence or new VU over the period (Tables 4, 5, 6, and 7).

VU diameters reduced over time ( $\mathrm{p}<0.001$; ANOVA); however, they did not vary significantly between day 60 and day 180 (p-value $=0.8903)$. The variables BMI, GSV reflux pattern, GSV diameter, reflux in other venous territories, age, comorbidities, side affected by VU, educational level, and occupation did not exhibit any significant influence. Ulcers that healed had smaller diameters at baseline than those that did not completely heal ( $\mathrm{p}$-value $=0.0336$ on day 60 and $p$-value $=0.0115$ on day $180 ;$ Mann-Whitney)

\section{GSV occlusion and reflux}

Initially, all GSVs had reflux. On day 60 , reflux had been eliminated in 15/22 GSVs (68.18\%; 95\%CI: $48.72-87.64 \%$ ) and on day 180 in $14 / 22 \mathrm{GSVs}$ (63.64\%; 95\%CI: 43.54-83.74\%). Total occlusion of GSVs ranged from 10/22 $(45.45 \%$; 95\%CI:

Table 6. Ulcer diameter (in centimeters) during follow-up.

\begin{tabular}{llclccc}
\hline \multicolumn{1}{c}{ Time } & $\mathbf{n}$ & Average & Sd* $^{*}$ & Min. & Median & Max \\
\hline Baseline & 22 & 4.11 & 3.4 & 1.00 & 3.00 & 14.00 \\
Day 60 & 22 & 1.15 & 2.52 & 0.00 & 0.00 & 8.00 \\
Day 180 & 22 & 1.18 & 2.65 & 0.00 & 0.00 & 10.00 \\
\hline
\end{tabular}

*Standard deviation.

Table 7. Comparison of baseline venous ulcer diameters (in centimeters) between groups with complete and incomplete healing.

\begin{tabular}{lrcccccc}
\hline \multicolumn{1}{c}{ VU healing } & $\mathbf{n}(\%)$ & Mean & $\mathbf{S d}^{*}$ & min & median & max & $\mathbf{p}$-value \\
\hline Healing at day 60 & & & & & & & \\
Complete & $15(68.18 \%)$ & 2.93 & 1.58 & 1.00 & 3.00 & 5.00 & 0.0336 \\
Incomplete & $7(31.82 \%)$ & 6.86 & 4.88 & 1 & 5.00 & 14.00 & \\
Healing at day 180 & & & & & & \\
Complete & $17(77.27 \%)$ & 2.94 & 1.64 & 1.00 & 3.00 & 5.00 & 0.0115 \\
Incomplete & $5(22.73 \%)$ & 8.4 & 4.83 & 3.00 & 9.00 & 14.00 & \\
\hline
\end{tabular}

Mann-Whitney test. *Standard deviation. 
Table 8. Comparison of baseline Great saphenous vein diameter between groups with partial and total GSV occlusion 60 days after treatment.

\begin{tabular}{lccc}
\hline & Partial Occlusion & Total Occlusion & p-value \\
\hline Baseline diameter Mean Sd ( $)$ & $13.8 \pm 3.0(\mathrm{n}=12)$ & $9.6 \pm 2.8(\mathrm{n}=10)$ \\
Baseline diameter Median (min - max) & $13.7(1.7-21)$ & $10.5(5.5-14.8)$ \\
\hline
\end{tabular}

Mann-Whitney test; Diameters in millimeters.

Table 9. Comparison of the baseline Great saphenous vein diameter between groups with partial and total GSV occlusion 180 days after treatment.

\begin{tabular}{lccc}
\hline & Partial Occlusion & Total Occlusion & p-value \\
\hline Baseline diameter Mean Sd $(n)$ & $13.22 \pm 3.2(n=15)$ & $9.4 \pm 3.3(n=7)$ & 0.01 \\
Initial diameter Baseline $(\min -\max )$ & $12.4(8.7-21)$ & $10.7(5.5-14.8)$ & \\
\hline
\end{tabular}

Mann-Whitney test; Diameters in millimeters.

$24.64-66.26 \%)$ on day 60 to $7 / 22(31.82 \%$; $95 \% \mathrm{CI}$ : $12.36-51.28 \%$ ) on day 180 . The GSVs that were completely occluded at the end of the study were smaller at baseline than those that were not completely occluded on day $60(\mathrm{p}=0.003$ Mann-Whitney) and on day 180 ( $\mathrm{p}=0.01$ Mann-Whitney). The variables number of sclerotherapy sessions, body mass index (BMI), age, educational level, gender, relationship with work, existence of comorbidities, pattern of venous reflux, side affected, and occurrence of adverse effects did not differ between groups. When the group in which there was residual reflux in the GSV was compared with the group in which reflux was eradicated on day 180 , they did not differ in relation to any of the variables studied (Mann-Whitney test and / or Fisher's test) (Tables 8 and 9).

\section{DISCUSSION}

Our protocol allowed selection of individuals considered to be poor candidates for surgery and who would benefit from elimination of venous reflux. Consecutive selection according to inclusion and exclusion criteria allowed the sample to be clinically homogenous and also enabled exclusion of patients at high risk of complications. No sample size calculations were conducted prior to the study. This was because multiple outcomes would be studied that would have different frequencies and would need samples of different sizes. Considering a healing rate of $91.3 \%$, as reported by Campos et al., our study would have needed 123 cases to attain a $95 \%$ confidence interval $(\mathrm{CI}) .{ }^{22}$ It is important to note that small sample sizes can lead to unreliable results. Our cohort study is a longitudinal research project that aims to establish a causal link between events. It does not enable efficacy to be determined. Efficay testing would require a comparative study with control group.

We studied patients who spontaneously sought treatment and there was no active screening for these patients. It is likely such patients were more symptomatic and had worse quality of life and so presented great improvement in this regard.

A non-parametric method was used to compare VU diameter, VCSS, and AQ results. Non-parametric methods are best suited to avoid errors in small patient samples with data that are not normally distributed.

The predominance of overweight women (68\%), obesity $(86 \%)$, comorbidities (55\%), low educational level ( $77 \%$ did not complete high school), and informal employment is similar to the population studied to validate the Brazilian version of the Aberdeen questionnaire. ${ }^{27,28}$

\section{Adverse effects}

Wright et al. ${ }^{19}$ reported 11 cases of deep vein thrombosis (DVT) (incidence of 5.3\%) when performing UGFS with up to $60 \mathrm{ml}$ of foam. European consensus guidelines recommend that foam volume should be limited to $10 \mathrm{ml}$ per session. ${ }^{30}$ We did not identify any severe adverse effects (AE). The most frequent $\mathrm{AE}$ was painful phlebitis in $4 / 22$ patients (18.18\%; 95\% CI: $20.06-34.3 \%) .2 / 22$ patients ( $9.09 \%$; 95\%CI: $0-21.10 \%$ ) had venous path hardening and hyperemia without pain. In a randomized trial with patients with GSV reflux but without VU, Thomasset et al. identified superficial phlebitis in $18 \%$ of patients, pain in $14 \%$, and skin staining in $28 \%$. We observed skin staining in 3/22 (13.64\%; 95\%CI: $0-27.98 \%)$. Women had more adverse reactions than men, which is similar to the data reported by Thomasset et al. ${ }^{31}$ In a systematic review of 69 studies, Jia et al. reported the following frequent complications: $4.7 \%$ phlebitis, $17.8 \%$ skin staining, and $25.6 \%$ local pain. ${ }^{32}$ These complications rates are similar to those identified in the present study.

\section{Quality of life}

We identified differences between men and women in terms of QoL improvement during the interval from 60 to 180 days after treatment. QoL is 
dependent on cultural factors and factors related to patients' expectations. We believe residual varicose veins, incomplete VU healing, and occurrence of skin staining may be the causes of worse QoL in women compared to men at the end of the study. All of the patients who had VU that were not fully healed at 180 days after treatment were women. There was also a higher proportion of women in the group who had AE. Other outcomes in our study had similar results for both genders. Occurrence of residual varicose veins after treatment was not studied. The AQ aesthetic assessment would indicate whether women's poor QoL was related to cosmetic factors.

\section{Clinical severity}

Higher severity related to larger VU was to be expected, since they are scored higher on the VCSS. The influence of age is also compatible with the progressive nature of CVI. Scott et al. observed that patients with CVI were older than those with varicose veins without CVI. ${ }^{33}$ Large cross-sectional studies, point to a higher prevalence of varicose veins in women, but do not indicate a higher prevalence of severe CVI among women. Scott et al. identified that $60 \%$ of VU patients were men while there was a predominance of women among those with varicose veins. However, multivariate analysis revealed that CVI patients were older, male and obese. The small sample in our study may be responsible for inconsistent results and since in our study we recruited patients treated at the hospital, our sample may not reveal the actual prevalence but, rather, reflect the greater demand for treatment among women. In the Edinburgh study, the severe forms of CVI did not show a predilection for gender after adjustment for age. ${ }^{34}$

\section{Ulcer healing}

We identified complete healing of $77.27 \%$ (CI 95\% $59.76-94.78 \%$ ) of VU and $90.90 \%$ (CI 95\% $78.89-100 \%$ ) of VU diameters reduced during the study. Before treatment, the VU initially had dimensions ranging from 1 to $14 \mathrm{~cm}$ (mean of $4.11 \mathrm{~cm}$ and median of $3.00 \mathrm{~cm}$ ). Barwel et al. identified healing of $65 \%$ of VU after treatment by saphenectomy or compression. ${ }^{12}$ VU healing rates after UGFS range from 71 to $92 \%$, but there are few randomized studies comparing sclerotherapy to clinical treatment and samples are also small. ${ }^{22,35,36}$ Campos Jr. et al. conducted a controlled study and demonstrated that UGFS and saphenectomy were similar, with healing of $91.3 \%$ of VU at 1-year follow-up. ${ }^{22}$ In a prospective cohort, Lloret et al. followed 180 UGFS-treated VU patients, 89 of whom (49.4\%) had GSV reflux. At six years, $172 \mathrm{VU}(95.6 \%)$ were healed. Lloret observed that deep venous reflux, VU open for more than 12 months, VU with an area of more than $6 \mathrm{~cm}^{2}$, lipodermatosclerosis, previous DVT, and bleeding were all associated with poorer cicatrization. ${ }^{37}$ Cabrera et al. also report worse results for healing of chronic VU and when there is deep venous reflux. ${ }^{36}$ The hypothesis that UGFS may be equivalent to surgery or thermoablation for averting recurrence of VU should be tested with long-term, controlled clinical trials with large groups. It is probable that USGFS is inferior for averting recurrence of VU, since foam sclerotherapy has higher rates of recanalization of treated veins and relapse of reflux.

\section{GSV Occlusion and elimination of reflux}

We observed residual reflux in 7/22 (95\%CI: $31.82 \%$ $12.36-51.28 \%)$ at 60 days and $8 / 22(36.36 \%$; 95\%CI: $27.45-45.27)$ at 180 days. Total occlusion occurred in 10/22 (45.45\%; 95\%CI: $24.65-66.26 \%)$ at 60 days; and $7 / 22$ (31.82\%; 95\% CI: $12.36-51.28 \%)$ at 180 days. GSVs with diameters from $5.5 \mathrm{~mm}$ to $21 \mathrm{~mm}(12 \mathrm{~mm}+/-3.62)$ were treated. The large caliber may be related to low rates of occlusion and elimination of reflux. Jia et al. identified $87 \%$ occlusion of trunk veins treated with foam sclerotherapy. ${ }^{32}$ In a randomized trial, Brittenden et al. identified 54.6\% occlusion of veins treated with sodium tetradecyl sulphate foam in a study that excluded GSVs with diameters exceeding $15 \mathrm{~mm}$ and in which only $2.8 \%$ of the patients had open or healed VU. ${ }^{20}$ We identified that GSVs that were completely occluded had smaller baseline diameters than GSVs that remained patent or partially patent, consistently, at both 60 days after treatment and at 180 days. Myers et al. prospectively studied 1189 sclerotherapy sessions performed in 489 patients with varicose veins, treating 454 GSVs. The occlusion rate after a single sclerotherapy session was $53.1 \%$. The occlusion rate of non trunk veins was higher than for GSVs. Veins with a diameter greater than $6 \mathrm{~mm}$ had worse results than those with diameters of $5 \mathrm{~mm}$ or less. The best results were observed in patients older than 70 years when foam sclerotherapy was used and when foam volume greater than $12 \mathrm{ml}$ and containing a higher concentration of sclerosants was used. ${ }^{25}$

\section{CONCLUSION}

The benefits in terms of quality of life, ulcer healing, and reduction of the severity of the venous disease without serious complications suggest that sclerotherapy is a valid option.

\section{REFERENCES}

1. Tatsioni A, Balk E, O 'Donell T, Lau J. Usual care in the management of chronic wounds: a review of the recent literature. JACS. 2007;205(4):617-624e57. 
2. Gloviczki P, Comerota AJ, Dalsing MC, et al. The care of patients with varicose veins and associated chronic venous diseases: clinical practice guidelines of the Society for Vascular Surgery and the American Venous Forum. J Vasc Surg. 2011;53(5, Suppl):2S-48S. http://dx.doi.org/10.1016/j.jvs.2011.01.079. PMid:21536172.

3. Nelzen O. Prevalence of venous leg ulcer: the importance of the data collection method. Phlebolymphology. 2008;15(4):143-50.

4. Maffei FH, Magaldi C, Pinho SZ, et al. Varicose veins and chronic venous insufficiency in Brazil: prevalence among 1755 inhabitants of a country town. Int J Epidemiol. 1986;15(2):210-7. http://dx.doi. org/10.1093/ije/15.2.210. PMid:3721683.

5. Portal da Saúde. Informações de Saúde (TABNET) [site na Internet]. Brasília: Ministério da Saúde; 2016 [cited 2016 Aug 29]. Available from: http://tabnet.datasus.gov.br/cgi/tabcgi.exe?sih/cnv/sxuf.def

6. AEPS InfoLogo. Base de dados da Históricos da Previdência Social [site na Internet]. Brasília: Ministério da Previdência Social; 2016 [cited 2016 Aug 26]. Available from: http://www3.dataprev.gov. br/infologo/GCON/CON10/CON10.php

7. Ghauri ASK, Taylor MC, Deacon JE, et al. Influence of a specialized leg ulcer service on management and outcome. $\mathrm{Br}$ J Surg. 2000;87(8):1048-56. http://dx.doi.org/10.1046/j.13652168.2000.01491.x. PMid:10931049.

8. Forssgren A, Fransson I, Nelzen O. Leg ulcer point prevalence can be decreased by broad-scale intervention: a follow-up crosssectional study of a defined geographical population. Acta Derm Venereol. 2008;88(3):252-6. http://dx.doi.org/10.2340/000155550433. PMid: 18480924.

9. Nelzen O. Leg ulcers: economic aspects. Phlebology. 2000;15(34):110-4. http://dx.doi.org/10.1177/026835550001500305.

10. Raju S, Hollis K, Neglen P. Use of compression stockings in chronic venous disease: patient compliance and efficacy. Ann Vasc Surg. 2007;21(6):790-5. http://dx.doi.org/10.1016/j.avsg.2007.07.014. PMid: 17980798 .

11. Mayberry JC, Moneta GL, Taylor LM Jr, Porter JM. Fifteen-year results of ambulatory compression therapy for chronic venous ulcers. Surgery. 1991;109(5):575-81. PMid:2020902.

12. Barwell JR, Davies CE, Deacon J, et al. Comparison of surgery and compression with compression alone in chronic venous ulceration (ESCHAR study): randomised controlled trial. Lancet. 2004;363(9424):1854-9. http://dx.doi.org/10.1016/S01406736(04)16353-8. PMid:15183623.

13. Reich-Schupke S, Murmann F, Altmeyer P, Stucker M. Compression therapy in elderly and overweight patients. Vasa. 2012;41(2):125-31. http://dx.doi.org/10.1024/0301-1526/a000175. PMid:22403131.

14. Franks PJ, Oldroyd MI, Dickson D, Sharp EJ, Moffatt CJ. Risk factors for leg ulcer recurrence: a randomized trial of two types of compression stocking. Age Ageing. 1995;24(6):490-4. http:// dx.doi.org/10.1093/ageing/24.6.490. PMid:8588538.

15. Garratt AM, Ruta DA, Abdalla MI, Russell IT. Responsiveness of the SF-36 and a condition-specific measure of health for patients with varicose veins. Qual Life Res. 1996;5(2):223-34. http://dx.doi. org/10.1007/BF00434744. PMid:8998491.

16. Gohel MS, Barwell JR, Taylor M, et al. Long term results of compression therapy alone versus compression plus surgery in chronic venous ulceration (ESCHAR): randomised controlled trial. BMJ. 2007;335(7610):83. http://dx.doi.org/10.1136/bmj.39216.542442. BE. PMid: 17545185

17. Mauck KF, Asi N, Elraiyah TA, et al. Systematic review and metaanalysis of surgical interventions versus conservative therapy for venous ulcers. J Vasc Surg. 2014;60(2 Suppl):60S-70S.e1-2.
18. Cabrera J, Cabrera J Jr, Garcia-Olmedo MA. Treatment of varicose long saphenous veins with sclerosant in microfoam form: longterm outcomes. Phlebology. 2000;15(1):19-23. http://dx.doi. org/10.1177/026835550001500103.

19. Wright D, Gobin JP, Bradbury AW, et al. Varisolve ${ }^{\curvearrowleft}$ polidocanol microfoam compared with surgery or sclerotherapy in the management of varicose veins in the presence of trunk vein incompetence: European randomized controlled trial. Phlebology. 2006;21(4):180-90. http://dx.doi.org/10.1258/026835506779115807.

20. Brittenden J, Cotton SC, Elders A, et al. at al. A randomized trial comparing treatments for varicose veins. N Engl J Med. 2014;371(13):1218-27. http://dx.doi.org/10.1056/NEJMoa1400781. PMid:25251616.

21. Rasmussen LH, Lawaetz M, Bjoern L, Vennits B, Blemings A, Eklof B. Randomized clinical trial comparing endovenous laser ablation, radiofrequency ablation, foam sclerotherapy and surgical stripping for great saphenous varicose veins. Br J Surg. 2011;98(8):1079-87. http://dx.doi.org/10.1002/bjs.7555. PMid:21725957.

22. Campos WJr, Torres IO, Silva ES, Casella IB, Puech-Leão P. A prospective randomized study comparing polidocanol foam sclerotherapy with surgical treatment of patients with primary chronic venous insufficiency and ulcer. Ann Vasc Surg. 2015;29(6):1128-35. http:// dx.doi.org/10.1016/j.avsg.2015.01.031. PMid:26004968.

23. Bountouroglou DG, Azzam M, Kakkos SK, Pathmarajah M, Young P, Geroulakos G. Ultrasound-guided foam sclerotherapy combined with saphenofemoral ligation compared to surgical treatment of varicose veins: early results of a randomized controlled trial. Eur J Vasc Endovasc Surg. 2006;31(1):93-100. http://dx.doi.org/10.1016/j. ejvs.2005.08.024. PMid:16233981.

24. Shadid N, Ceulen R, Nelemans P, et al. Randomized clinical trial of ultrasound-guided foam sclerotherapy versus surgery for the incompetent great saphenous vein. Br J Surg. 2012;99(8):1062-70. http://dx.doi.org/10.1002/bjs.8781. PMid:22627969.

25. Myers KA, Jolley D, Clough A, Kirwan J. Outcome of ultrasoundguided sclerotherapy for varicose veins: medium-term results assessed by ultrasound surveillance. Eur J Vasc Endovasc Surg. 2007;33(1):116-21. http://dx.doi.org/10.1016/j.ejvs.2006.09.005. PMid:17067832.

26. O'Donnell TF Jr, Passman MA, Marston WA, et al. Management of venous leg ulcers: clinical practice guidelines of the Society for Vascular. J Vasc Surg. 2014;60(2, Suppl):3S-59S. http://dx.doi. org/10.1016/j.jvs.2014.04.049. PMid:24974070.

27. Leal FJ, Couto RC, Pitta GBB, et al. Tradução e adaptação cultural do Questionário Aberdeen para Veias Varicosas. J Vasc Bras. 2012;11(1):34-42. http://dx.doi.org/10.1590/S1677-54492012000100007.

28. Leal FJ, Couto RC, Pitta GBB. Validação no Brasil de Questionário de Qualidade de Vida na Doença Venosa Crônica (Questionário Aberdeen para Veias Varicosas no Brasil/AVVQ-Brasil).J Vasc Bras. 2015;14(3):241-7. http://dx.doi.org/10.1590/1677-5449.0025.

29. Rutherford RB, Padberg FT Jr, Comerota AJ, Kistner RL, Meissner $\mathrm{MH}$, Moneta GL. Venous severity scoring: An adjunct to venous outcome assessment. J Vasc Surg. 2000;31(6):1307-12. http:// dx.doi.org/10.1067/mva.2000.107094. PMid:10842165.

30. Rabe E, Breu FX, Cavezzi A, et al. European guidelines for sclerotherapy in chronic venous disorders. Phlebology. 2014;29(6):338-54. http:// dx.doi.org/10.1177/0268355513483280. PMid:23559590.

31. Thomasset SC, Butt Z, Liptrot S, Fairbrother BJ, Makhdoomi KR. Ultrasound guided foam sclerotherapy: Factors associated with outcomes and complications. Eur J Vasc Endovasc Surg. 2010;40(3):389-92. http://dx.doi.org/10.1016/j.ejvs.2010.04.007. PMid:20547076. 
32. Jia X, Mowatt G, Burr JM, Cassar K, CookJ, Fraser C. Systematic review of foam sclerotherapy for varicose veins. Br J Surg. 2007;94(8):925 36. http://dx.doi.org/10.1002/bjs.5891. PMid:17636511.

33. Scott TE, Lamorte WW, Gorin DR, Menzoian JO. Risk factors for chronic venous insufficiency: a dual case-control study. J Vasc Surg. 1995;22(5):622-8. http://dx.doi.org/10.1016/S0741-5214(95)700501. PMid:7494366.

34. Evans CJ, Fowkes FG, Ruckley CV, Lee AJ. Prevalence of varicose veins and chronic venous insufficiency in men and women in the general population: Edinburgh Vein Study.J Epidemiol Community Health. 1999;53(3):149-53. http://dx.doi.org/10.1136/jech.53.3.149. PMid:10396491.

35. Kulkarni SR, Slim FJ, Emerson LG, et al. Effect of foam sclerotherapy on healing and long-term recurrence in chronic venous leg ulcers. Phlebology. 2013;28(3):140-6. http://dx.doi.org/10.1258/ phleb.2011.011118. PMid:22422794.

36. Cabrera J, Redondo P, Becerra A, et al. Ultrasound-guided injection of polidocanol microfoam in the management of venous leg ulcers. Arch Dermatol. 2004;140(6):667-73. http://dx.doi.org/10.1001/ archderm.140.6.667. PMid:15210456.

37. Lloret P, Redondo P, Cabrera J, Sierra A. Treatment of venous leg ulcers with ultrasound-guided foam sclerotherapy: healing, long-term recurrence and quality of life evaluation. Wound Repair Regen. 2015;23(3):369-78. http://dx.doi.org/10.1111/wrr.12288. PMid:25816893.
Correspondence Guilherme Camargo Gonçalves de Abreu Rua Padre Almeida, 515, conj. 74, $7^{\circ}$ andar CEP 13025-251 - Campinas (SP), Brasil

Tel.: +55 (19) 32555481

E-mail: gcgabreu@gmail.com

Author information

GCGA - MD, vascular surgeon, Departamento de Angiologia e Cirurgia Vascular, Pontifícia Universidade Católica de Campinas (PUCCampinas); MSc degree in Health Science, PUC-Campinas.

OC) - MD, vascular surgeon, Departamento de Angiologia e Cirurgia Vascular, Pontifícia Universidade Católica de Campinas (PUC-

Campinas); MSc degree in Health Science, PUC-Campinas. MFMA - MD, vascular surgeon, Departamento de Angiologia e Cirurgia Vascular, Pontifícia Universidade Católica de Campinas (PUCCampinas).

JLBA - MD, head and neck, thoracic and digestive surgeon, Departamento de Cirurgia Geral, Pontifícia Universidade Católica de Campinas (PUC-Campinas); MSc and PhD degree in Surgery, Universidade de Campinas (UNICAMP).

Author contributions Conception and design: GCGA, JLBA, OC) Analysis and interpretation: GCGA, JLBA, OCJ

Data collection: GCGA Writing the article: GCGA, MFMA Critical revision of the article: GCGA, JLBA, OC) Final approval of the article*: GCGA, OCJ, MFMA, JLBA Statistical analysis: GCGA Overall responsibility: GCGCA

*All authors have read and approved of the final version of the article submitted to J Vasc Bras. 